Preprint Manuscript: Dehdari Ebrahimi Z., Bridgelall R., Momenitabar M. (2021) Extending Micromobility Deployments: A Concept and Local Case Study. In: Stahlbock R., Weiss G.M., Abou-Nasr M., Yang CY., Arabnia H.R., Deligiannidis L. (eds) Advances in Data Science and Information Engineering. Transactions on Computational Science and Computational Intelligence. Springer, Cham. https://doi.org/10.1007/978-3-030-71704-9_19. ISBN: 3030717038, 9783030717032.

\title{
Extending Micromobility Deployments: A Concept and Local Case Study
}

\author{
Zhila Dehdari Ebrahimi \\ Department of Transportation Logistics \\ \& Finance, North Dakota State \\ University, Fargo, ND 58108-6050 \\ ORCID 0000-0001-7256-0881.
}

\author{
Raj Bridgelall \\ Department of Transportation Logistics \\ \& Finance, North Dakota State \\ University, Fargo, ND 58108-6050 \\ ORCID 0000-0003-3743-6652.
}

\author{
Mohsen Momenitabar \\ Department of Transportation Logistics \\ \& Finance, North Dakota State \\ University, Fargo ND 58108-6050 \\ ORCID 0000-0003-2568-1781.
}

\begin{abstract}
-in a recent phenomenon that refers to the use of small human-or electric-powered vehicles such as scooters and bikes to travel short distances, and sometimes to connect with other modes of transportation such as bus, train, or car. Deployments in major cities of the world have been both successful and challenging. This paper reviews the evolution of services from shared bicycles, dockless systems, and shared electric scooters. The authors evaluated benefits, deficiencies, and factors in adoption to inform more rigorous and extensive geospatial analysis that will examine intersections with land-use, public transit, socio-economic demographics, road networks, and traffic. This work conducted exploratory spatial data analysis and correlation of publicly available datasets on land use, trip production, traffic, and travel behavior. Data from Washington D.C. served as a case study of best practices for scaling deployments to meet the social, economic, and mobility needs of the city.
\end{abstract}

Keywords: bike sharing; dockless bike sharing; docked bike sharing

\section{INTRODUCTION}

The number of vehicles and trips are ever-increasing with population growth and technology evolution. Consequently, new modes of transportation are emerging to fill gaps in mobility and accessibility. has emerged as a new form of transportation - a category of vehicles that weigh less than five hundred kilograms and covers distances of less than five miles. Figure 1 shows how solutions fit within the spectrum of travel parameters.

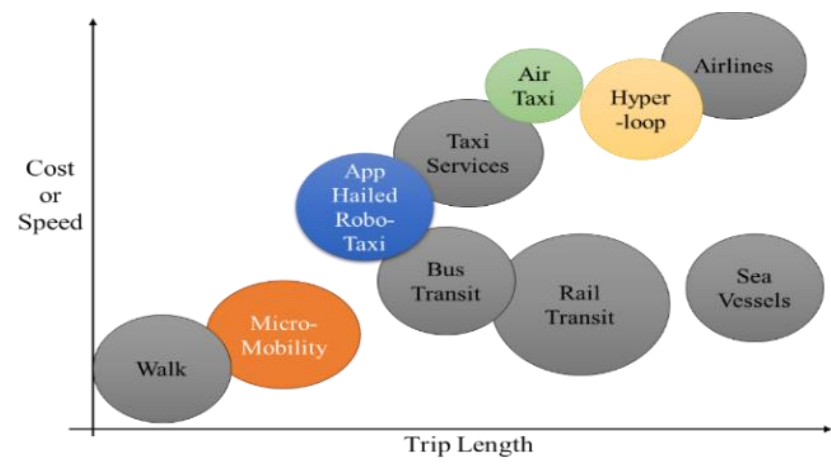

Figure 1. Evolving modes of transportation.

Other modes that are emerging include app-hailed Robo-cab, air taxis, and hyper loops [1]. This paper focuses on the history, impacts, and implications of the category where accessibility, flexibility, and affordability are its main advantages. Vehicles in the category are human- or electricpowered and include docked bikes, dockless bikes, e-scooters, and other emerging modes [2]. The main characteristic of docked bike sharing is that users must unlock the vehicle from a designated station and return it to any other designated station that has space. In contrast, users of dockless bike sharing use an app to enable the vehicle for usage, and then stow the vehicle anywhere after using it. The app tracks the position of available vehicles using the standard positioning service (SPS) of the global positioning system (GPS). The escooter is a more recent form of within the dockless category. Recent deployments of e-scooters brought both opportunities and challenges for cities around the globe. In some cases, companies are struggling to sustain their deployments as cities demand more attention to safety, clutter, and equity. As evolved, it has had a large impact on the environment, society, and livability. The next three subsections review the history of bike sharing and its evolution towards e-scooter sharing, the benefits and deficiencies of the new mode, and factors in their adoption.

\section{HISTORY}

The first bike sharing system emerged in the 1960's and has since completed three generations of evolution. The first generation began in 1965 with 50 unlocked bikes in Amsterdam for free use by the public [3]. The second generation began in the early 1990's as coin-deposit systems where users can unlock bikes with a small cash deposit [4]. A third generation replaced those systems by using membership cards to unlock bikes from docking stations. Transformations in service models took place over time because of differences in benefits, deficiencies, capital costs, and operating costs [4].

As of May 2011, there were an estimated 136 bicycle sharing programs in 165 cities around the world with 237,000 bikes on the roads [5]. By 2013, bike-sharing programs had launched in more than 500 cities in 49 nations with a combined fleet of more than 500,000 bikes [6]. Bike-sharing in the Americas emerged in Canada, Mexico, the United States, Argentina, Brazil, and Chile. Asia currently has the fastest-growing bike sharing market with services deployed in China, South Korea, and Taiwan. The 
main pull for bike sharing deployments are traffic management and air pollution control, which are major challenges in China. The network of urban roads in China is complex and people have many different choices of travel modes. The introduction of bike sharing in China spurred a mode shift from single occupancy motor vehicles. The availability of bike-sharing, and the increasing accessibility of mobile technology influenced an integrated shared mobility app that combines cars and bikes [7]. Riders now mainly use public bicycles to commute, travel home during lunch breaks, and for after-work shopping [8]. These developments reduced traffic congestion, environmental noise, the frequency of crashes, the severity of injuries, and the level of physical inactivity.

Bike share in the United States ramped up very quickly. There were 35 million trips taken in 2017, which was $25 \%$ more than trips in 2016. At the end of 2017, five major dockless bike-share companies operated in 25 cities and suburbs. The inventory of shared bikes increased from 42,500 in 2016 to nearly 100,000 in 2017 , with the majority of those being dockless. During the latter half of 2017, companies added 44,000 new dockless bikes in cities around U.S., accounting for $44 \%$ of all shared bikes in the nation [9]. At the end of 2018, the popularity of e-scooters has increased relative to shared-bikes, and the use of dockless bike sharing decreased from 2017 to 2018 [10]. Reference [11] analyzed the challenge of using the new kind of public transportation mode in ten cities and found that among the urban transport modes, the e-scooter is most effective in reducing the use of private cars. However, e-scoters could create conflicts over space, speed, and safety when introduced without consideration of policies. The use of e-scooters started in Santa Monica and Austin in 2017. The number of e-scooters in Washington D.C increased from 5,235 to at least 10,000. In San Francisco the increase was from 2,500 to at least 4,000. Urban communities like D.C. grant operational licenses through open application forms [12].

Reference [13] studied bike sharing in Seattle, USA, which is the first city to adopt dockless bike share. The case study found that inadequate system scale, station density, geographic coverage area, ease of use, and pricing structure contributed to the struggle for adoption. The study demonstrated that explicit options made by system designers and policymakers instead of local market or environmental factors lead to failure. Regardless of membership type, weather is less of a disutility for dockless scooter share (DSS) users than for Station Based Bike share (SBBS) users [14]. Gas prices have a positive impact on use. Reference [15] reviewed the barriers of dockless bike-sharing systems for travel behavior of user, user experience, and relevant social impacts of dockless bike-sharing systems. Reference [15] suggests that the dockless design of bike-sharing systems remarkably improves users' experiences at the end of their bike trips because used need not return it to a designated dock. Furthermore, the high flexibility and efficiency of dockless bike-sharing makes the integration with public transit an efficient option for first/last-mile solutions. The GPS tracking device embedded in each dockless shared bike allow for the collection of large-scale route data, which allow researchers to evaluate travel behavior in new ways.

The first e-bike was introduced in 2017 and it was a new challenge for the government of Japan. They introduced a new "sandbox" program to support the innovative technologies and business in Japan. This program covers the different area like healthcare service, mobility, transportation, and financial systems. Reference [16] found that 129 companies were working under the program.

is so new that public agencies have not yet included them as a transport mode in travel surveys, hospital admission records, and police crash databases [17]. Even so, the various forms of are proliferating based on differences in utilitarian needs [18]. An emerging mode of are hover boards which have two wheels and a cross-board that the user stands on. Another mode is VEEMO - a three-wheeled enclosed motorcycle-style vehicle that uses solar energy [19]. One advantage is that it shelters the user from bad weather. Evolving concepts could converge with the trends of electrification, sharing, connectivity, and autonomy [20]. Safety and well-being will likely improve as governments put in place guidelines for shared Micro-mobility [21]. Reference [22] found that the CORVID-19 virus caused a shift from public transit in New York City towards Micro-mobility modes.

\section{BENEFITS AND DEFICIENCIES}

Recent analysis determined that bikes and e-scooters are best suited for short distance trips or for connection to longerdistance public transit modes for journey completion [23]. Using for last-mile connectivity to transit will help cities to decrease traffic congestion and environmental pollution. The e-scooter mode of has benefits and deficiencies similar to shared bikes. The benefits are that they can spur a mode shift to public transportation. A report by the National League of Cities (NLC) found that helps communities save money on travel and leads to a more sustainable environment globally by reducing green-house-gas emissions [24]. Dockless modes of have the advantages of lower cost for portions of the trip and flexibility to transfer to other modes for longer legs of a trip. However, the vehicle must be safe, and the road infrastructure must be suitable for safe travel. The NLC study found that trip productivity can increase if various vehicles are close to metro stations, taxi stations, and ride-hailing stations. In general, modes promote physical activity, which provides health benefits [25].

The National Association of City Transportation Officials (NACTO) in the United States. Analyzed data for different modes of in six cities, including statistics such as the number of trips, the purpose of using a mode, the duration of each trip, and the average cost per trip. They found that more people used bike sharing than e-scooters for work trips and for connecting to other types of public transportation modes. The study found that most people used e-scooters for weekend shopping trips in the peak hours from 11 a.m. to 12 noon. Usage of e-scooters in the afternoon and into the evening is higher than that of shared-bikes. Most people use bike-share for week-day trips. Using trip distance and duration, NACTO calculated the average cost per trip for e-scooter and dockedbike as $\$ 3.50$ and $\$ 1.25$, respectively. Consequently, companies have been offering discounts for low-income users of e-scooters.

The deficiencies of modes of transport are that individual or environmental factors contribute to the rate of accidents and injuries. Users of e-scooters tend to pay less attention to their surroundings while using their cellphones. Riders use escooters at uncontrolled speeds and drivers ignore them [24]. This increases the risk of accidents and injuries. This concern 
led Washington, D.C., to establish speed-limit rules for escooters. The use of dockless scooters also creates clutter in cities because users stow them anywhere and even discard some in lakes and oceans [24]. The lack of infrastructure such as special routes to accommodate e-scooters can interfere with pedestrian traffic and create safety issues. These shortcomings point to the growing need for companies to revise their usage and stowage policies to reduce interference with motor vehicle and pedestrian traffic. Consequently, cities need to have clearly defined paths to separate traffic flows from pedestrians, to separate faster electrically assisted vehicles from foot pedal bikes, and to designated stowage areas where clutter can be minimized without reducing their accessibility [26] [27].

\section{FACTORS IN ADOPTION}

A study in Norway chose 66 persons at random to utilize an e-bike for a restricted period and compared the results with a control group of 160 persons [28]. The study found that e-bike trips expanded from 0.9 to 1.4 per day, distance from $4.8 \mathrm{~km}$ to $10.3 \mathrm{~km}$, and transport mode share from $28 \%$ to $48 \%$, with the control group showing no change in bike usage. Their results also showed that the effect of e-bike increased with time and had more impact on women than on the men. Another study showed that in countries with a cycling culture, such as Denmark, e-bikes resulted in a mode shift from cars [29]. The study found that these impacts are lower in regions with no provisions for cycling, such as in north America and Australia. A study in Sweden found that an increased use of e-bikes for private journeys will result in energy efficiency gains [30].

Studies around the globe found that environmental conditions such as weather and terrain topography can influence adoption [31] [32] [33]. A Singapore study modeled the impact of fleet size, environment infrastructure, and weather condition on the preference for dockless bike sharing and found that weather conditions and infrastructure had the main impact on usage rate [34]. An Australian study showed that strong winds and rainfall deters the use of bike sharing and consequently decreases the number of trips [35]. A Canadian study found that weather conditions such as humidity, precipitation, and snow reduced the demand for bike sharing in Toronto, Canada [36].

Many studies sought to determine non-weather factors that influence the choice of bike sharing over other modes such as public transit and taxis. The main findings are that factors affecting usage rates include sociodemographic, population, density of buildings, proximity to the central business district, street geometry, proximity to water, accessibility to trails, length of bike lanes, distance to other stowage sites, transportation law and policies involving helmet and license requirements [37] [38] [8] [39] [40]. A few studies examined gender attitudes in the use of bike sharing. Several studies revealed that more men used bikes than women [41] [42]. In contrast, other studies found that women were more interested in using bike sharing than men, especially on weekdays [43] [44]. However, women who care for children are more likely to rely on private vehicles [45].

The remainder of this paper is organized into four sections. Section 2 presents best practices and various considerations for data analysis to inform deployment decisions. Section 3 describes relevant data from Washington D.C. to provide some insights into the data analytics. Section 4 discusses the

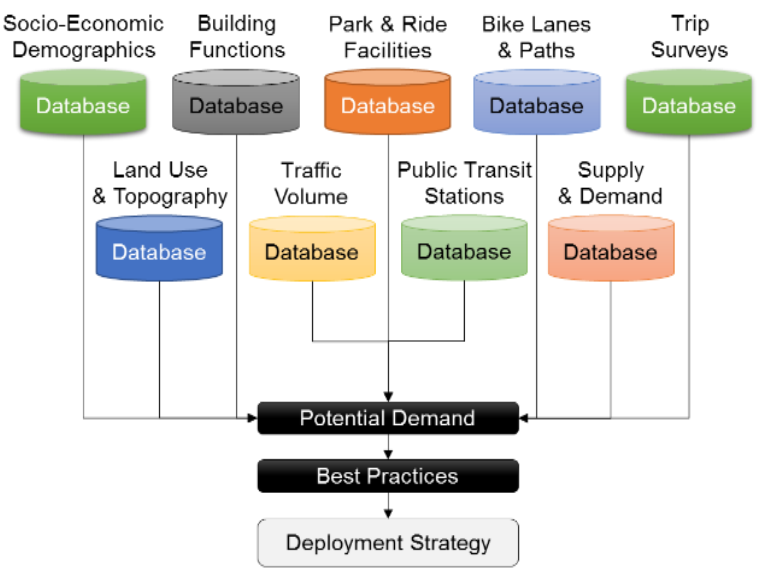

Figure 2. Analysis of potential demand using available GIS data.

results from the case study in terms of recommendations for deployment and expansion. Section 5 summarizes the significance to the work and provides concluding remarks.

\section{METHOD}

Cities throughout the world have different designs, infrastructure, land use, budget, socio-demographics, climate, travel behavior, and levels of technology deployments that influence their approaches to adoption. Even within a locality, the urban landscape can differ across areas and influence land rent [46]. In general, the transportation network of a city center is complex. The density of transportation services tends to be heavier in city centers than in the outskirts. This geospatial variation in transport services impacts travel behavior and mode choice.

This research suggests a research strategy to determine opportunities for deployment and scaling in a selected city. The strategy starts by gathering available data about existing solutions deployed, their spatial-temporal distribution relative to public transit services, and areas of high trip generation and trip attraction. Figure 2 illustrates that such an analysis would begin with the synthesis of information from different social, behavioral, and geospatial data sources. Subsequently, decisions about where to deploy must be filtered with best practices that involve working closely with the city.

A synthesis of knowledge from the literature points to the following strategies as best practices for service providers to sustain and scale deployments:

1) Understand the needs of the city, the intentions behind them, and their compatibility with the business model of the service provider.

2) Work with cities upfront to implement solutions that:

- complement public transportation services

- minimize interference with motor vehicle, human-powered vehicles, and pedestrian traffic

- avoid stowage clutter in the middle of sidewalks or foot paths

- enforce the avoidance of restricted access areas

- make the service equitable and affordable for low-income riders

- maintain a privacy policy that is compliant with state and federal laws

- Implement liability mechanisms that are fair. 
3) Implement usage policies that promote the safe operation of all types of vehicles provided.

4) Balance supply and demand, both spatially and temporally, to meet the needs of the city.

5) Remove disabled vehicles and maintain vehicles regularly to ensure operational safety and reliability.

6) Share usage data with cities to forge a partnership in both near-term and long-term urban planning.

7) Provide a multilingual website and all-hour customer support.

8) Collaboratively promote the service with the city's public engagement resources.

Common data sources are available from open-source data services that most cities currently host. Database services include information on the following:

1) Land use - derived from zoning maps that show the distribution of residences, businesses, neighborhood boundaries, street layout, bicycle lanes, pedestrian walkways, and public transit stations such as light rail, bus stops, subways, and taxi hubs.

2) Trip generators - derived from Geographical Information Systems (GIS) containing data on building usage, their location, and their relative distances to public transportation services. GIS also show a distribution of parks, community centers, and tourist attractions.

3) Trip behavior-derived from census data on population, sociodemographic, and trip surveys.

A central tenant of the finding from the literature review is that sharing usage data will help governments understand evolving travel behavior to inform long-term infrastructure planning that can support and sustain the adoption of services. Currently, companies allocate stations for docked vehicles or rebalance dockless vehicles based on the population within each area. For example, Figure 3 shows the current distribution of Capital Bike share docking stations in Washington, D.C. [47].

Analyzing data about the type of usage for different sections of a city can reveal points where benefits sustained or stopped [48]. Demand analysis begins by identifying highdemand public transportation routes. Assessing demand at different times and stations will inform strategies for allocating services to minimize overall travel delay and to avoid overstocking. This tactic is based on the finding that many travelers use services to access public transportation for trip continuation. Databases on existing supply and demand includes pickup and drop-off times, travel trajectories, speeds, positions relative to transit locations, bike lanes, and bike trails. Knowledge about the spatial and temporal ebb and flow of supply and demand is an essential part of informing vehicle redistribution strategies.

\section{DATA FOR THE CASE STUDY}

Dockless bike shares in Washington, D.C. began in September 2017 and reached 155,000 trips by 2018 [49]. This was in comparison to $1,220,000$ docked bike trips from the company for the same period. The District Department of Transportation (DDOT) evaluates the success of shared deployments based on equity, data sharing, and company viability. The DDOT found that there is significant inequity of the current deployments. Analysis of a publicly available database indicates that the highest concentration of those age 20-29 are in Noma, Dupont Circle, and downtown whereas the concentration for age 30-39 are around the Capitol Hill, National Mall, downtown, and southwest Washington [50]. These age groups currently tend to be the largest users of services.

Micromobility modes have become some of the most affordable forms of public transportation in major cities of the world [10]. Hence, analyzing the socio-demographic factors in each zone of a city can inform decisions about the redistribution of services. Areas that have a high to median income are Palisades, Chevy Chase, Friendship Heights, and Tenley town [51]. Most low- or moderate-income Washington, D.C. residents are in the south, east, middle and north parts of the city. Hence, more bike lanes are needed in those areas. companies can focus more on the east and south parts where there are fewer bike sharing or transit stations.



Figure 3. Distribution of Capital Bike Share stations and bike availability (Capital Bike share, 2018)

Micro-mobility usage has the potential to relieve traffic in various parts of Washington D.C. Figure 4 shows relative bicycle traffic volumes in Washington, D.C. [52].
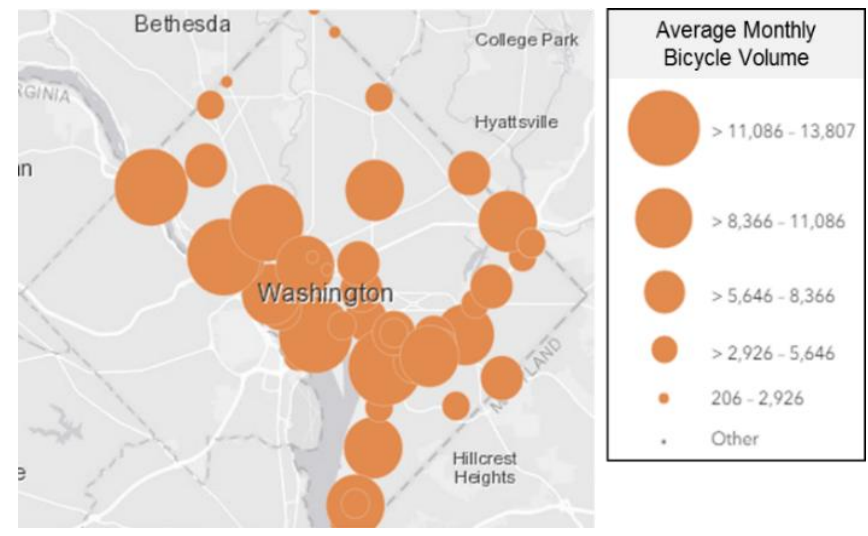

Figure 4. Traffic monitor stations and average monthly bicycle volume (DDOT, 2019).

The dataset associated with the chart contains the locations of permanent vehicle count stations and weigh-in-motion stations. The dataset includes the street segment ID, traffic sensor type, and a count of the number of bicycles passing 


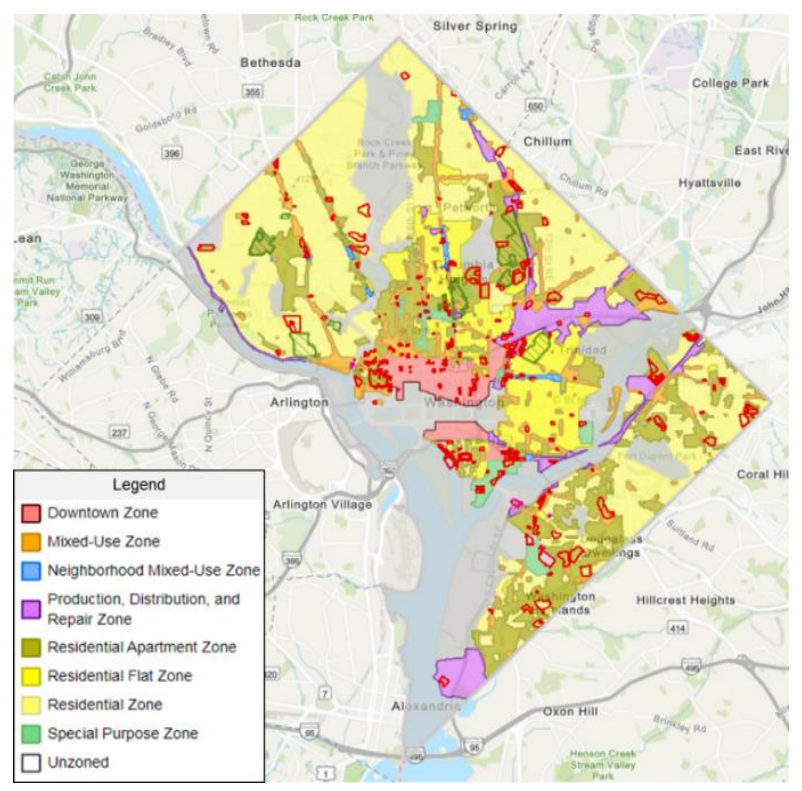

Figure 6. Official zoning for Washington D.C. (DCOZ, 2019).

those sensors. The highest bicycle traffic volume is around downtown, Capitol Hall, Georgetown, Fox hall Crescent, and Southwest Washington. Many public recreation sites like the National Park and Downtown exhibit high demand for services.

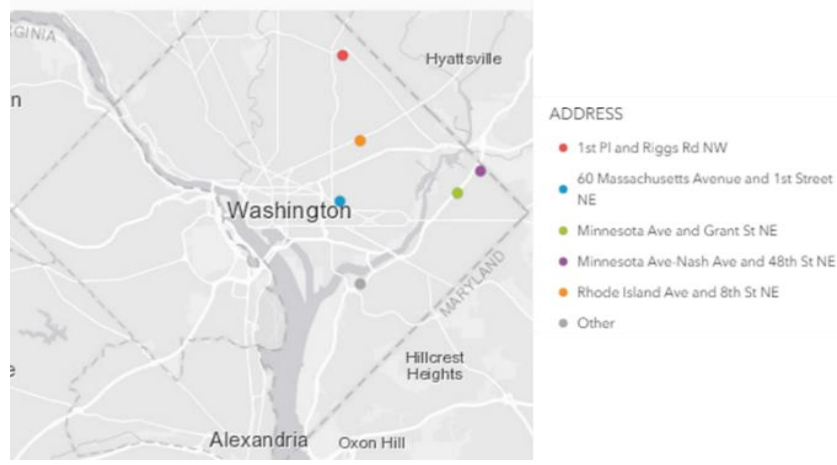

Figure 5. Park-and-Ride locations (DDOT, 2019).

Accessibility to public transportation can help with trip completion where infrastructure is lacking, or the travel time is too long. The Park and Ride points shown in Figure 5 contain lots where commuters can park their private vehicles and commute to the city center or other areas. The figure shows that park-and-ride points are only in the downtown and northeast areas. The dataset used to create the chart is from the Washington, D.C. Open-GIS Database [53].

Figure 6 shows that bike lanes are in downtown, Bloomingdale, 16th Street Heights, Capitol Hill, and towards the south-east [54]. Based on topographical databases, it is surmised that fewer bike lanes are in the north because of high elevations in that area. Figure 7 shows that most bicycle trips in Washington D.C. are between 2 and 5.5 miles [55]. Figure 8 shows the current land use and zoning restrictions of Washington D.C. [56].

The pattern indicates that once they have demonstrated viability in the city centers, companies can expand service in the residential areas of the north, east and south zones where there is a high rate of apartment dwellings. In those areas, the residential zones are flat and have space to deploy services.

\section{RESULTS}

A synthesis of the land use, demographic, traffic, ride path capacity, park-and-ride facility locations, public transit access, and demand factors for Washington, D.C. suggest that companies can focus, in the short term, on deploying most of

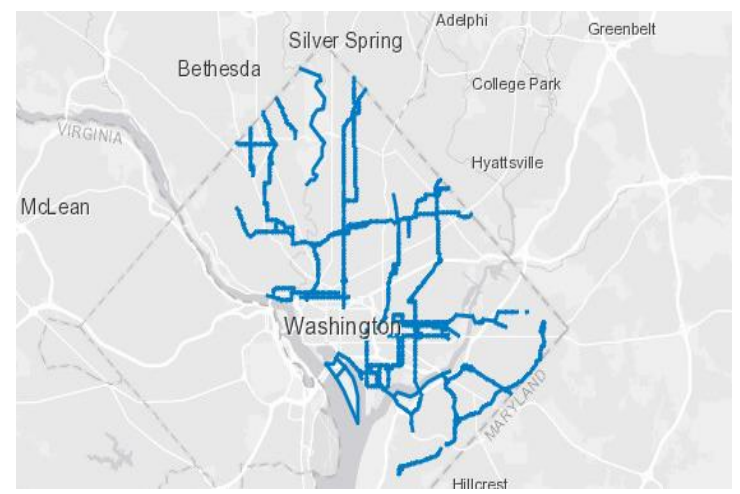

Figure 7. Trip Distance (Newebcreations, 2019)

their services in the areas around downtown, West, Fox hall Crescent, and Southwest Washington. This distribution will allow the companies to reach the highest number of potential customers and grow the market. A higher service rate in those areas would increase customer satisfaction and spur adoption. Based on the geospatial analysis, the areas that currently have a low level of biking facilities are Fort Totten, Bright wood, Chevy Chase, Tenley town, Hill East, and Carver/Langston. So, companies should work with the city to develop long-term strategies for service expansion in those areas. A phased deployment plan will minimize initial costs at the time when companies need to demonstrate viability.

Currently, the main cost drivers of dockless deployments are the man hours needed to charge and rebalance vehicles, modulate the fleet size, and maintain support at all hours. Agencies can first focus longer term investments to build more bike lanes in the southern portion of Washington, D.C., where there are low elevations, high traffic volumes, and low incomes. Similarly, investing and creating more opportunities for deployments in the north zone where traffic is moderate, bike trails are few, and terrain is flat will help to enhance both mobility and accessibility. Adding services in the east where the rate of park-and-ride usage is high will help longerdistance commuters transfer to public transportation, decrease pollution, and promote greater equity for the area's lowincome residents.

\section{CONCLUSIONS}

This study reviewed the different dimensions of services, factors that could influence demand, and best practices for extending and sustaining deployments. The authors used publicly available data from Washington, D.C., as a case study to examine the potential opportunities for growing services. The behavioral and geospatial datasets mined included the distributions of park-and-ride facilities, socioeconomic data, topography, land use, and current bicycle traffic. The best practices and analytical strategy of where and when to invest will help companies increase their profitability while helping to improve transportation sustainability. Increasing the rate of services by addressing their potential drawbacks can have positive consequences such as the reduction of traffic congestion, the reduction of pollution, and the enhancement of transportation equity. This work is the first exploratory stage of research in preparation for a more rigorous geospatial 
analysis of deployments as a function of land-use, socioeconomic demographics, road networks, and traffic.

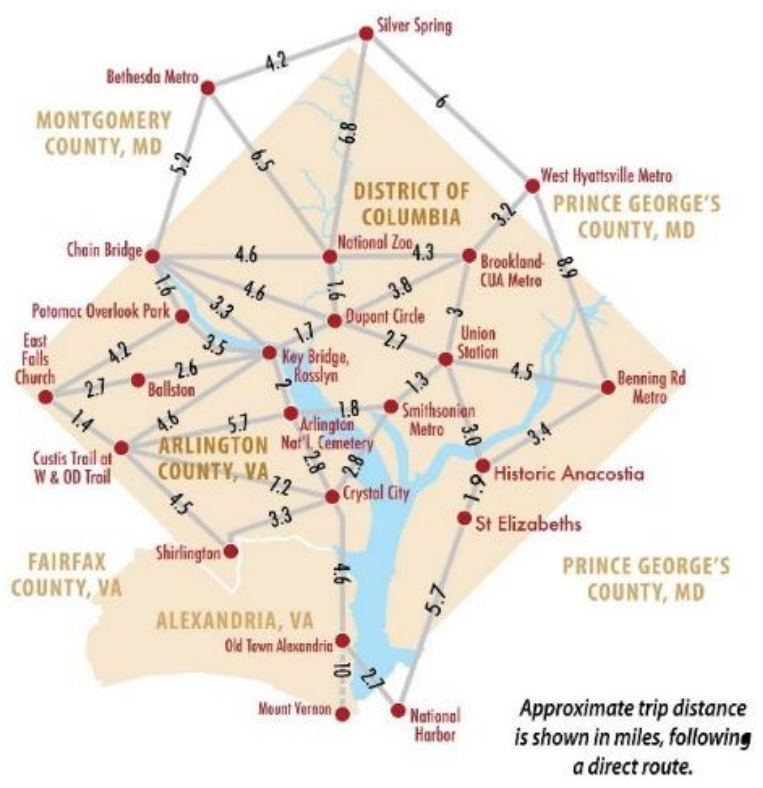

Figure 8. Bike lanes in Washington, D.C. (DDOT, 2019)

\section{REFERENCES}

[1] NGA, "Governors Staying Ahead of the Transportation Innovation Curve: A Policy Roadmap for States," National Governors Association (NGA), Washington, D.C., 2018.

[2] NACTO, "Guidelines for Regulating Shared Mobility: Version 2," National Association of City Transportation Officials (NACTO), Washington, D.C., 2019.

[3] F. Soriguera, V. Casado and E. Jiménez, "A simulation model for public bike-sharing systems," Transportation research procedia, vol. 33, pp. 139-146, 2018

[4] P. DeMaio, "Bike-sharing: History, impacts, models of provision and future," Journal of Public Transportation, vol. 12, no. 4, pp. 41-56, 2009.

[5] S. Shaheen and S. Guzman, "Worldwide bike sharing," Access Magazine, vol. Fall 2011, no. 39, pp. 22-27, 2011.

[6] J. Larsen, "Bike-Sharing Programs Hit the Streets in Over 500 Cities Worldwide," 2013. [Online]. Available: http://www.earthpolicy.org/mobile/releases/update112. [Accessed 2811 2019].

[7] B. Jiang, S. Liang, Z.-R. Peng, H. Cong, M. Levy, Q. Cheng, T. Wang and J. V. Remais, "Transport and public health in China: the road to a healthy future," The Lancet, vol. 390, no. 10104, pp. 1781-1791, 2017.

[8] Y. Zhang, T. Thomas, M. Brussel and M. Maarseveen, "Exploring the impact of built environment factors on the use of public bikes at bike stations: Case study in Zhongshan, China," Journal of Transport Geography, vol. 58, pp. 59-70, 2017.

[9] NATCO, "Bike Share in the U.S.: 2017," National Association of City Transportation Officials (NACTO), 2017.

[10] NACTO, "Shared Micromobility in the U.S.: 2018," National Association of City Transportation Officials (NACTO), 2018.

[11] S. Gössling, "Integrating e-scooters in urban transportation: Problems, policies, and the prospect of system change," Transportation Research Part D: Transport and Environment, vol. 79, 2020

[12] D. Zipper, "The Frenzied Era of E-Scooters Is Over," 27 Feburary 2020. [Online]. Available: https://slate.com/business/2020/02/e-scootersregulations-bird-lyft-lime-cities.html.

[13] D. M. Luke Peters, "The death and rebirth of bikesharing in Seattle: Implications for policy and system design," Transportation Research Part A: Policy and Practice, pp. 208-226, 2019.

[14] Z. Z. J. W. G. B. Hannah Younes, "Comparing the Temporal Determinants of Dockless Scooter-share and Station-based Bike-share in Washington, D.C.," Transportation Research Part A: Policy and Practice, pp. 308-320, 2020.
[15] D. v. L. \&. D. E. Zheyan Chen, "Dockless bike-sharing systems: what are the implications?" Transport Reviews, 2020.

[16] G. O. JAPAN, "How the Japanese Government's New "Sandbox" Program Is Testing Innovations in Mobility and Technology," 11 Feburary 2020. [Online]. Available: https://hbr.org/sponsored/2020/02/how-the-japanese-governments-newsandbox-program-is-testing-innovations-in-mobility-and-technology.

[17] E. Fishman and C. Cherry, "E-bikes in the Mainstream: Reviewing a Decade of Research," Transport Reviews, vol. 36, no. 1, pp. 72-91, 2015.

[18] K. Lovejoy and S. Handy, "Developments in Bicycle Equipment and Its Role in Promoting Cycling as a Travel Mode," in City Cycling, J. Pucher and R. Buehler, Eds., Cambridge, Massachusetts, The MIT Press, 2012, pp. 75-104.

[19] MOVMI, "The Micromobility Conferences, California 2019," movmi Shared Transportation Services Inc. 2019, 11 2019. [Online]. Available: http://movmi.net/micromobility-conference-2019/. [Accessed 2711 2019].

[20] E. Hannon, S. Knupfer, S. Stern, B. Sumers and J. T. Nijssen, "An Integrated Perspective on the Future of Mobility, Part 3: Setting the Direction Towards Seamless Mobility," McKinsey \& Company, 2019.

[21] I. T. Forum, "Safe Micromobility," International Transport Forum, Paris, 2020.

[22] G. Kuntzman, "BOOM! New Citi Bike Stats Show Cycling Surge is Real - But Mayor is Not Acting," 12 March 2020. [Online]. Available: https://nyc.streetsblog.org/2020/03/12/boom-new-citi-bike-stats-showcycling-surge-is-real-but-mayor-is-not-acting/.

[23] R. Zarif, D. M. Pankratz and B. Kelman, "Small is beautiful: Making micromobility work for citizens, cities, and service providers," 2019. [Online]. Available: https://www2.deloitte.com/us/en/insights/focus/future-ofmobility/micro-mobility-is-the-future-of-urban-transportation.html. [Accessed 2711 2019].

[24] N. DuPuis, J. Griess and C. Klein, "Micromobility in Cities: A History and Policy Overview," National League of Cities, Washington, D.C., 2019.

[25] N. A. Gallagher, "The influence of neighborhood environment, mobility limitations, and psychosocial factors on neighborhood walking in older adults," The University of Michigan, Michigan, 2010.

[26] C. Nuworsoo, E. Cooper and K. Cushing, "Integration of Bicycling and Walking Facilities into the Infrastructure of Urban Communities," Mineta Transportation Institute, San Jose, 2012.

[27] A. Ajao, "Electric Scooters and Micro-Mobility: Here's Everything You Need To Know," 2019. [Online]. Available: https://www.forbes.com/sites/adeyemiajao/2019/02/01/everything-youwant-to-know-about-scooters-and-micro-mobility/\#796971415de6.

[28] A. Fyhri and N. Fearnley, "Effects of e-bikes on bicycle use and mode share," Transportation Research Part D: Transport and Environment, vol. 36, pp. 45-52, 2015.

[29] S. Haustein and M. Møller, "Age and attitude: Changes in cycling patterns of different e-bike user segments," International Journal of Sustainable Transportation, vol. 10, no. 9, pp. 836-846, 2016.

[30] L. Winslott Hiselius and A. Svensson, "Could the increased use of ebikes (pedelecs) in Sweden contribute to a more sustainable transport system?" in 9th International Conference on Environmental Engineering (ICEE), 2014.

[31] B. E. Saelens, J. F. Sallis and L. D. Frank, "Environmental correlates of walking and cycling: findings from the transportation, urban design, and planning literatures," Annals of Behavioral Medicine, vol. 25, no. 2, pp. 80-91, 2003.

[32] R. Cervero and M. Duncan, "Walking, bicycling, and urban landscapes: evidence from the San Francisco Bay Area," American Journal of Public Health, vol. 93, no. 9, pp. 1478-1483, 2003.

[33] S. D. Lawson and B. Morris, "Out of cars and onto bikes: what chance?" Traffic Engineering \& Control, vol. 40, no. 5, pp. 272-276, 1999.

[34] Y. Shen, X. Zhang and J. Zhao, "Understanding the usage of dockless bike sharing," International Journal of Sustainable Transportation, vol. 12, no. 9, pp. 686-700, 2018.

[35] J. Corcoran, T. Li, D. Rohde, E. Charles-Edwards and D. MateoBabiano, "Spatio-temporal patterns of a Public Bicycle Sharing Program: the effect of weather and calendar events," Journal of Transport Geography, vol. 41, pp. 292-305, 2014.

[36] W. El-Assi, M. S. Mahmoud and K. N. Habib, "Effects of built environment and weather on bike sharing demand: a station level analysis of commercial bike sharing in Toronto," Transportation, vol. 44, no. 3, pp. 589-613, 2017. 
[37] C. M. d. Chardon, G. Caruso and I. Thomas, "Bicycle sharing system 'success' determinants," Transportation Research Part A: Policy and Practice, vol. 100, pp. 202-214, 2017.

[38] X. Wang, G. Lindsey, J. E. Schoner and A. Harrison, "Modeling Bike Share Station Activity: Effects of Nearby Businesses and Jobs on Trips to and from Stations," Journal of Urban Planning and Development, vol. 142, no. 1, p. 04015001, 2015.

[39] A. Faghih-Imani and N. Eluru, "Examining the impact of sample size in the analysis of bicycle-sharing systems," Transportmetrica A: Transport Science, vol. 13, no. 2, pp. 139-161, 2017.

[40] D. G. Chatman, "Residential Choice, the Built Environment, and Nonwork Travel: Evidence Using New Data and Methods," Environment and Planning A: Economy and Space, vol. 41, no. 5, pp. 1072-1089, 2009.

[41] B. Caulfield, M. O'Mahony, W. Brazil and P. Weldon, "Examining usage patterns of a bike-sharing scheme in a medium sized city," Transportation Research Part A: Policy and Practice, vol. 100, pp. 152161, 2017.

[42] E. Fishman, "Bikeshare: A review of recent literature," Transport Reviews, vol. 36, no. 1, pp. 92-113., 2016.

[43] Y. Zhao, L. Chen, C. Teng, S. Li and G. Pan, "Green Bicycling: A Smartphone-Based Public Bicycle Sharing System for Healthy Life," Atlanta, 2013

[44] D. Buck, R. Buehler, P. Happ, B. Rawls, P. Chung and N. Borecki, "Are bikeshare users different from regular cyclists? A first look at short-term users, annual members, and area cyclists in the Washington, DC, region," Transportation Research Record, vol. 2387, no. 1, pp. 112-119, 2013.

[45] S. Rosenbloom and E. Burns, "Gender differences in commuter travel in Tucson: implications for travel demand management programs," Transportation Research Record, vol. 1404, pp. 82-90, 1993.

[46] J. Wu, S. Wang, Y. Zhang, A. Zhang and C. Xia, "Urban landscape as a spatial representation of land rent: A quantitative analysis," Computers, Environment and Urban Systems, vol. 74, pp. 62-73, 2019.

[47] Capital Bikeshare, "Find a station," 2019. [Online]. Available: https://secure.capitalbikeshare.com/map/. [Accessed 2611 2019].

[48] S. Bouton, E. Hannon, L. Haydamous, S. Ramanathan, B. Heid, S Knupfer, T. Nauclér, F. Neuhaus and J. T. Nijssen, "Urban commercial transport and the future of mobility," McKinsey \& Company, 2017.

[49] G. Chaffin, "Dockless bikeshare helped grow the total shared bicycle trips in DC," 2018. [Online]. Available: https://ggwash.org/view/67638/dockless-bikeshare-helped-grow-thetotal-shared-bicycle-trips-in-dc.

[50] Statistical Atlas, "Age and Sex in Washington, District of Columbia," 2019. [Online]. Available: https://statisticalatlas.com/place/District-ofColumbia/Washington/Age-and-Sex. [Accessed 2511 2019].

[51] Statistical Atlas, "Household Income in Washington, District of Columbia," 2018. [Online]. Available: https://statisticalatlas.com/place/District-ofColumbia/Washington/Household-Income. [Accessed 2511 2018].

[52] DDOT, "Traffic Monitoring Stations," Washington D.C. Department of Transportation (DDOT), 2019. [Online]. Available: https://opendata.dc.gov/datasets/a87c1b9a71e143a4914e3c384bda2d3a _92. [Accessed 2611 2019].

[53] DDOT, "Park and Ride Points," Washington D.C. Department of Transportation (DDOT), 2019. [Online]. Available: https://opendata.dc.gov/datasets/park-and-ride-points. [Accessed 2611 2019].

[54] DDOT, "Open Data DC," District of Columbia Department of Transportation (DDOT), 2019. [Online]. Available: https://opendata.dc.gov/datasets/bicycle-lanes. [Accessed 2611 2019].

[55] Newebcreations, "District of Columbia Bicycle Map," 2019. [Online]. Available: https://maps-washington-dc.com/dc-bikemap\#\&gid=1\&pid=1. [Accessed 2611 2019].

[56] DCOZ, "Official Zoning Map," 2019. [Online]. Available: http://maps.dcoz.dc.gov/zr16/. [Accessed 2711 2019].

[57] Y. Zhang, M. Brussel, T. Thomas and M. v. Maarseveen, "Mining bikesharing travel behavior data: An investigation into trip chains and transition activities," Computers, Environment and Urban Systems, vol. 69, pp. 39-50, 2018. 